\title{
High Rates of Undiagnosed and Uncontrolled Hypertension Upon a Screening Campaign in Rural Rwanda: a Cross- sectional Study
}

\author{
Evariste Ntaganda \\ Rwanda Biomedical Center \\ Regine Mugeni ( $\sim$ pacisreg@gmail.com ) \\ Rwamagana Provincial Hospital

\section{Emmanuel Harerimana} \\ Partners in Health (PIH), Inshuti Mu Buzima

\section{Gedeon Ngoga} \\ Partners in Health (PIH), Inshuti Mu Buzima

\section{Symaque Dusabeyezu} \\ Partners in Health (PIH), Inshuti Mu Buzima
}

Francois Uwinkindi

Rwanda Biomedical Center

Jean Nepo A. Utumatwishima

Rwamagana Provincial Hospital

\section{Eugene Mutimura}

National Council for Science and Technology (NCST)

Victor G. Davila-Roman

Washington University in St. Louis

Kenneth Schechtman

Washington University in St. Louis

Aurore Nishimwe

University of Rwanda

\section{Laurence Twizeyimana}

Regional Alliance for Sustainable Development

\section{Angela L. Brown}

Washington University in St. Louis

Todd W. Cade

Duke University School of Medicine

\section{Marcus Bushaku}

Regional Alliance for Sustainable Development

\section{Lisa De Las Fuentes}

Washington University in St. Louis

\section{Dominic Reeds}

Washington University in St. Louis

\section{Marc Twagirumukiza}

Ghent University 


\section{Research Article}

Keywords: High blood pressure, Hypertension, Screening, Rwanda

Posted Date: November 9th, 2021

DOI: https://doi.org/10.21203/rs.3.rs-1025198/v1

License: (9) This work is licensed under a Creative Commons Attribution 4.0 International License. Read Full License

Version of Record: A version of this preprint was published at BMC Cardiovascular Disorders on April 26th, 2022. See the published version at https://doi.org/10.1186/s12872-022-02606-9. 


\section{Abstract}

Background: Hypertension remains the major risk factor for cardiovascular diseases (CVDs) worldwide with a prevalence and mortality in low- and middle-income countries (LMICs) among the highest. The early detection of hypertension risk factors is a crucial pillar for CVD prevention.

Design and method: This cross-sectional study included 4284 subjects, mean age $46 \pm 16$ SD, $56.4 \%$ females and mean BMI 26.6 \pm 3.7 SD. Data were collected through a screening campaign in rural area of Kirehe District, Eastern of Rwanda, with the objective to characterize and examine the prevalence of elevated blood pressure (BP) and other CVD risk factors. An adapted tool from the World Health Organization STEPwise Approach was used for data collection. Elevated BP was defined as $\geq 140 / 90 \mathrm{~mm} / \mathrm{Hg}$ and elevated blood glucose as blood glucose $\geq 100 \mathrm{mg} / \mathrm{dl}$ after a six-hours fast.

Results: Of the sampled population, 21.2\% $(n=910)$ had an elevated BP at screening; BP was elevated among individuals not previously known to have HTN in $18.7 \%(n=752)$. Among individuals with a prior diagnosis of HTN, $62.2 \%(n=158$ of 254) BP was uncontrolled. Age, weight, smoking, alcohol history and waist circumference were associated with BP in both univariate analyses and multivariate analysis.

Conclusion: High rates of elevated BP identified through a health screening campaign in this Rwandan district were surprising given the rural characteristics of the district and relatively low population age. These data highlight the need to implement an adequate strategy for the prevention, diagnosis, and control of HTN that includes rural areas of Rwanda as part of a multicomponent strategy for CVD prevention.

\section{Background}

Cardiovascular diseases (CVDs) are the leading cause of morbidity and mortality worldwide ${ }^{1,2}$ and approximately $80 \%$ of all cardiovascular deaths occur in low- and middle-income countries ${ }^{1,3}$. By 2030 , cardiovascular deaths are projected to increase to 23 million globally ${ }^{4}$ and double in Sub-Saharan Africa (SSA) from 1 million deaths in $2013^{5}$.

Hypertension (HTN) is the most prevalent risk factor for CVD mortality worldwide ${ }^{3}$. Although hypertension is a welldocument public health threat in developing countries, population-based data on HTN prevalence is scarce from SSA. Based on one report, the estimated prevalence of HTN in SSA is $16.2 \%$, ranging from $10.6 \%$ in Ethiopia to $29.6 \%$ in Ghana. In SSA, the prevalence of HTN is also higher in urban (20.7\%) compared with rural $\left(13.7 \%\right.$ ) areas ${ }^{6}$, a difference generally attributed to lifestyle changes commonly associated increasing urbanization (physical inactivity, obesity, smoking, and alcohol consumption) ${ }^{7}$. Similar to other LMICs, Rwanda is experiencing epidemiological transition in urban areas with changes in lifestyle behaviors which portends increased healthcare burden, morbidity, and mortality from CVDs.

Early detection and management remain a key cost-effective strategy for the prevention of chronic CVDs ${ }^{6,8,9}$. However, there is a lack of data on the prevalence of CVD risk factors among adults living in remote rural areas which are less geographically accessible. This fundamental data gap hampers efforts to characterize the CVD risk profile in mainly rural regions, further impeding efforts to establish appropriate preventive measures targeting these underserved populations ${ }^{1,10}$. To bridge this gap, this study aimed to measure the rates of and risk factors for HTN in people living in a rural area of Rwanda through a screening campaign the Kirehe District, an eastern province of Rwanda.

\section{Methods}

\section{Study design and procedures}

This was a cross-sectional study that included adult ( $\geq 18$ years) Rwandan people who participated in campaign on voluntary basis for five days from 23rd to 29th September, 2018. The study design followed the other reported screening 
studies design ${ }^{11}$. In addition it has integrated elements from Health Beliefs Model (HBM) ${ }^{12}$ to explore the rates and predictors of HTN in the community. The screening was conducted by trained volunteers (medical students and nurses) from health centers ( $\mathrm{HCs}$ ) in the Kirehe district hospital catchment area. The core role of the Kirehe district leadership was to arrange with local authorities to sensitize and invite people for screening by using local and public communications and radio publicity spots. The screening site was designed by HCs leadership and staff of Rwanda Biomedical Centre (RBC), a government institution under the Ministry of Health responsible for implementing health polices and health services in the community.

\section{Study setting}

The study was conducted in 8 sectors in the Kirehe District that were systematically selected. The Kirehe District, one of the rural area districts situated in Eastern province of Rwanda bordering Tanzania, covers a total area of 1,118.5 Km² with a population of 340,983 ( $52 \%$ female) according to National Institute of Statistics of Rwanda (NISR). Ninety percent ( $90 \%$ ) of the economic activity in the district depends on agriculture and livestock ${ }^{13}$.

\section{Data collection}

Data collection was done after verbal consent of participants by using an adapted World Health Organization STEPwise Approach to NCD Risk Factor Surveillance tool ${ }^{14}$. Data collected included demographics, social history of alcohol intake and smoking, prior history of hypertension, and time since last meal. Measurements included anthropometrics, blood pressure and blood glucose. After a resting in a seated position for 5 minutes, blood pressure (BP) was taken three times separated by 1 minute with a calibrated and automated BP machine (Omron M2, Kyoto, Japan). The mean of the $2 \mathrm{nd}$ and 3 rd readings was recorded. Waist circumference (WC) was measured in triplicate at the level of the midpoint between the lower margin of the last palpable rib and the top of the iliac crest after expiration using a $203 \mathrm{~cm} \mathrm{Secaß} \mathrm{measuring} \mathrm{tape} \mathrm{(all}$ Seca GmbH \& Co. KG., Hamburg, Germany); the mean of the three WC measures was used for analysis ${ }^{15}$. Weight was measured using a digital Seca ${ }^{\circledR} 813$ scale and height using a Seca ${ }^{\circledR} 213$ stadiometer. As the BP measures were taken casually and do not necessarily reflect a well-established hypertension diagnosis ${ }^{16}$, we used the term of "Elevated BP" to reflect a systolic BP greater than or equal to $140 \mathrm{mmHg}$ and/or a diastolic BP greater than or equal to $90 \mathrm{mmHg} .{ }^{17,18} \mathrm{This}$ definition of elevated BP has nothing do with the definition of hypertension staging, used in some guidelines ${ }^{16}$. Data on the use of anti-hypertensive medications was not collected; a separate question surveyed whether the subject had ever been diagnosed with HTN.

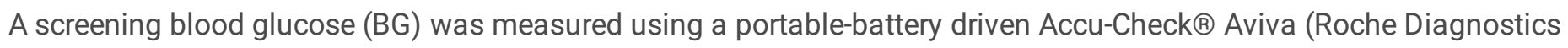
$\mathrm{GmbH}$, Mannheim, Germany); the number of fasting hours as recorded. As the BG measures were taken casually and do not necessarily reflect a well-established diabetes diagnosis ${ }^{19}$, we used the term "elevated blood glucose" to reflect glycaemia greater than or equal to $100 \mathrm{mg} / \mathrm{dL}^{19-21}$. Participants who had elevated BP or self-reported use of HTN medications or had elevated BG were referred to the nearest health center for regular follow-up. Those individuals with normal BP were counselled on NCD risk reduction for primary prevention. The blood glucose and blood pressure results were communicated to participants immediately. The study was conducted in accordance with the principles of the Declaration of Helsinki and local Rwandan regulations.

\section{Statistical methods and data analysis}

Data was captured by a study team person using spreadsheet software program (Microsoft Excel, Microsoft Corporation, 2018), then de-identified and transferred to STATA 15.5 Version (Stata Corporation, College Station, TX) for analysis. Data are presented as mean \pm standard deviation (SD) or percentage (number). Comparisons were performed by unpaired t-tests,

one-way ANOVA and $\chi^{2}$-test as appropriate. Results with $P$-values $<0.05$ were considered statistically significant. Univariate and multivariate regression analyses were used to assess relationships between different risk factors and the presence of elevated BP in the total population and in subgroups defined by the absence or presence of a prior diagnosis of HTN. 
We inspect the correlations between the predictors, using a correlation map to assess the collinearity, and highly correlated variables were entered one by one to test the best model. All variables in bivariate analyses with $p$-value $<0.05$ were considered for inclusion in multivariate regression model.

\section{Results}

Participant characteristics by blood pressure category

A total of 4,284 participants in Kirehe district completed a 5-day screening program as part of routine monthly physical activity national program. The participants were largely middle-aged (mean age: $46 \pm 16$ years, range: $18-98$ years), female $(56,4 \%)$, mildly overweight, and the majority had a history of alcohol intake (Table 1). Females were younger than males (mean age: $45 \pm 16$ vs. $47 \pm 16$ years; $p<0.001$ ). More than one-third of participants ( $34 \%$ ) reported history of smoking; $14.8 \%$ $(n=636)$ were current smokers and $19.2 \%(n=821)$ were former smokers.

Of the 4284 individuals in the sampled cohort, $21.2 \%(n=910)$ had elevated BP, including 158 of $254(62.2 \%)$ individuals with a prior diagnosis of HTN, and 752 of 4030 (18.7\%) without a prior diagnosis of HTN. Some known cases were controlled hypertensive with a normal BP with mean systolic blood pressure (SBP) of $127 \pm 19 \mathrm{mmHg}$, and mean diastolic pressure (DBP) of $77 \pm 11 \mathrm{mmHg}$ (Supplementary material 1). The proportion of new discovery of elevated BP progressively increased with advancing age: $19.1 \%$ in $45-54$ year olds, $27.2 \%$ in $55-64$ year olds, and $33.4 \%$ among those with age $>65$ years (Figure 1).

Gender was similar between Normal BP and Elevated BP categories (Table 1). Age, weight, body mass index (BMI), and waist circumference were all higher in the Elevated BP categories compared with the Normal BP (all $p<0.001$ ). Fasting blood glucose concentration was significantly higher in the All Elevated BP and Elevated BP among Non-Known Hypertensive subjects. The prevalence of smoking history, alcohol consumption, and elevated blood glucose are all higher in the Elevated BP categories compared with the Normal BP category (all $p<0.005$ ).

The distribution of BP category was similar across BMI categories (Figure 2). An elevated BG was found in 18.2\% ( $n=779)$ of participants, with a greater proportion of elevated BP among those participants with BG $\geq 100 \mathrm{mg} / \mathrm{dL}$ (Figure 3). Among the 713 participants (16.6\%) with a reported diagnosis of diabetes, $616(79.1 \%)$ had a BG $\geq 100 \mathrm{mg} / \mathrm{dL}$; BG was elevated in 163 participants without a reported diagnosis of diabetes (3.8\% of the total screened population, $4.6 \%$ among participants without a reported diagnosis of diabetes) (Supplementary material 1). 
Table 1

Participants' characteristics and elevated Blood Pressure (BP) outcome

\begin{tabular}{|c|c|c|c|c|c|c|c|c|}
\hline \multirow{6}{*}{$\begin{array}{l}\text { Participant } \\
\text { Characteristics }\end{array}$} & \multirow{6}{*}{$\begin{array}{l}\text { Total } \\
\text { Screened } \\
\text { Population } \\
\mathrm{N}=4284\end{array}$} & \multicolumn{7}{|c|}{ Comparisons by Elevated Blood Pressure ${ }^{a}$} \\
\hline & & \multirow{5}{*}{$\begin{array}{l}\text { Normal BP } \\
\mathrm{n}=3374\end{array}$} & \multirow{3}{*}{\multicolumn{2}{|c|}{$\begin{array}{l}\text { All Elevated BP } \\
\mathrm{n}=910(21.2 \%)\end{array}$}} & \multirow{3}{*}{\multicolumn{2}{|c|}{$\begin{array}{l}\text { Elevated BP in Known } \\
\text { Hypertensive Subjects } \\
n=158(62.2 \%) \text { of } 254\end{array}$}} & \multirow{3}{*}{\multicolumn{2}{|c|}{$\begin{array}{l}\text { Elevated BP in } \\
\text { Non-Known } \\
\text { Hypertensive } \\
\text { Subjects } \\
n=752(18.7 \%) \text { of } \\
4030\end{array}$}} \\
\hline & & & & & & & & \\
\hline & & & & & & & & \\
\hline & & & \multirow{2}{*}{$\begin{array}{l}\text { Mean } \pm \\
\text { SD } \\
\text { or \% (n) }\end{array}$} & \multirow[t]{2}{*}{${ }^{b} p$-value } & \multirow{2}{*}{$\begin{array}{l}\text { Mean } \pm \\
\text { SD } \\
\text { or } \%(n)\end{array}$} & \multirow[t]{2}{*}{${ }^{b} p$-value } & $\begin{array}{l}\text { Mean } \pm \\
\text { SD }\end{array}$ & \multirow[t]{2}{*}{${ }^{b} p$-value } \\
\hline & & & & & & & or $\%(n)$ & \\
\hline Female (\%)(n) & $\begin{array}{l}56.4( \\
2417)\end{array}$ & $\begin{array}{l}57.0( \\
1922)\end{array}$ & $\begin{array}{l}54.4 \\
(495)\end{array}$ & 0.165 & $54.4(86)$ & 0.530 & $\begin{array}{l}54.4 \\
(409)\end{array}$ & 0.197 \\
\hline Age (years) & $46 \pm 16$ & $44 \pm 15$ & $55 \pm 15$ & $<0.001$ & $56 \pm 14$ & $<0.001$ & $55 \pm 15$ & $<0.001$ \\
\hline Height (cm) & $166 \pm 4$ & $166 \pm 4$ & $166 \pm 4$ & 0.486 & $166 \pm 4$ & 0.193 & $166 \pm 4$ & 0.180 \\
\hline Weight (kg) & $73.6 \pm 9.3$ & $72.8 \pm 8.2$ & $76.7 \pm 12$ & $<0.001$ & $76.2 \pm 12.1$ & $<0.001$ & $76.7 \pm 12$ & $<0.001$ \\
\hline $\mathrm{BMI}\left(\mathrm{kg} / \mathrm{m}^{2}\right)$ & $26.6 \pm 3.7$ & $26.4 \pm 3.3$ & $27.7 \pm 4.6$ & $<0.001$ & $27.8 \pm 4.7$ & $<0.001$ & $27.7 \pm 4.7$ & $<0.001$ \\
\hline $\begin{array}{l}\text { Waist } \\
\text { Circumference } \\
(\mathrm{cm})\end{array}$ & $74.4 \pm 16.6$ & $72.7 \pm 15.6$ & $80.4 \pm 18.6$ & $<0.001$ & $80.0 \pm 18.2$ & $<0.001$ & $80.5 \pm 18.6$ & $<0.001$ \\
\hline $\begin{array}{l}\text { Smoking } \\
\text { history (\%)(n) }\end{array}$ & $\begin{array}{l}34.0( \\
1457)\end{array}$ & 26.6(896) & $\begin{array}{l}61.6 \\
(561)\end{array}$ & $<0.001$ & $61.4(97)$ & $<0.001$ & $\begin{array}{l}61.7 \\
(464)\end{array}$ & $<0.001$ \\
\hline $\begin{array}{l}\text { Alcohol history } \\
(\%)(n)\end{array}$ & $\begin{array}{l}63.8( \\
2732)\end{array}$ & 58.1(1959) & $\begin{array}{l}84.9 \\
(773)\end{array}$ & $<0.001$ & $\begin{array}{l}82.9 \\
(131)\end{array}$ & $<0.001$ & $\begin{array}{l}85.4 \\
(642)\end{array}$ & $<0.001$ \\
\hline $\begin{array}{l}\text { Systolic BP } \\
\text { (mmHg) }\end{array}$ & $127 \pm 18$ & $119 \pm 12$ & $153 \pm 14$ & $<0.001$ & $153 \pm 16$ & $<0.001$ & $153 \pm 13$ & $<0.001$ \\
\hline $\begin{array}{l}\text { Diastolic BP } \\
(\mathrm{mmHg})\end{array}$ & $76 \pm 11$ & $72 \pm 8$ & $88 \pm 9$ & $<0.001$ & $89 \pm 9$ & $<0.001$ & $88 \pm 9$ & $<0.001$ \\
\hline $\begin{array}{l}\text { Blood glucose } \\
\text { (mg/dL) }\end{array}$ & $101 \pm 22$ & $100 \pm 21$ & $105 \pm 25$ & $<0.001$ & $103 \pm 30$ & 0.051 & $105 \pm 24$ & $<0.001$ \\
\hline $\begin{array}{l}\text { c Elevated } \\
\text { blood glucose } \\
(\%)(n)\end{array}$ & 18.2(779) & $16.5(558)$ & $\begin{array}{l}24.3 \\
(221)\end{array}$ & $<0.001$ & $7.6(12)$ & 0.003 & $\begin{array}{l}27.8 \\
(208)\end{array}$ & $<0.001$ \\
\hline \multicolumn{9}{|c|}{$\begin{array}{l}\text { a Elevated Blood pressure was defined as a systolic blood pressure (SBP) } \geq 140 \mathrm{mmHg} \text { and/or diastolic blood pressure } \\
(\mathrm{DBP}) \geq 90 \mathrm{mmHg}\end{array}$} \\
\hline \multicolumn{9}{|c|}{${ }^{b}$ Comparison by unpaired t-test or $\chi^{2}$ vs. Normal BP } \\
\hline \multicolumn{9}{|c|}{${ }^{c}$ Elevated blood glucose $\geq 100 \mathrm{mg} / \mathrm{dL}$ after minimum 6-hour fast } \\
\hline
\end{tabular}

Table caption: Table 1 combine both descriptive data on the total screened population (first column) and univariate participants characteristics comparison between each time the normal BP group vs elevated BP, vs poorly controlled BP and vs new discovered cases BP groups 
Independent risk factors of Elevated BP in the 3 groups: General screened population, known hypertensive population and the newly discovered elevated BP sub-groups.

Table 2 presents a multivariate analysis results of risk factors in the Normal BP group vs each of the three Elevated BP categories: All Elevated BP, Elevated BP in Known Hypertensive subjects, and Elevated BP in Non-Known Hypertensive subjects. The findings revealed that advanced age was independently associated with progressively increased risk of having elevated BP in all three comparisons (all $p<0.001$ ). The relationship between Elevated BP category with overweight $\left(25 \leq \mathrm{BMl}<30 \mathrm{~kg} / \mathrm{m}^{2}\right)$ and obesity $\left(\mathrm{BMI} \geq 30 \mathrm{~kg} / \mathrm{m}^{2}\right)$, weight, waist circumference, and fasting blood glucose were less consistent. Current smoking, alcohol consumption, and fasting blood glucose are significant predictors of Elevated BP in multivariate models (Table 2). 
Table 2

Participants characteristics associated Elevated BP in multivariate analysis.

\begin{tabular}{|c|c|c|c|c|c|c|}
\hline & \multicolumn{2}{|c|}{$\begin{array}{l}\text { a Normal BP vs. } \\
\text { All Elevated BP }\end{array}$} & \multicolumn{2}{|c|}{$\begin{array}{l}\text { Normal BP vs. Elevated } \\
\text { BP in } \\
\text { Known Hypertensive } \\
\text { Subjects }\end{array}$} & \multicolumn{2}{|c|}{$\begin{array}{l}\text { Normal BP vs. Elevated BP in } \\
\text { Non-known Hypertensive } \\
\text { Subjects }\end{array}$} \\
\hline & OR (95\%Cl) & $p$-value & OR (95\% Cl) & $p$-value & OR (95\% Cl) & $p$-value \\
\hline \multicolumn{7}{|l|}{ Age (Years) } \\
\hline $18-44$ & Ref & & Ref & & Ref & \\
\hline $45-54$ & $\begin{array}{l}1.8 \times[1.46- \\
2.36]\end{array}$ & $<0.001^{*}$ & $\begin{array}{l}1.87[1.10- \\
3.18]\end{array}$ & $0.021^{\star}$ & $1.76[1.35-2.88]$ & $<0.001$ * \\
\hline $55-64$ & $\begin{array}{l}3.05[2.41- \\
3.85]\end{array}$ & $<0.001^{*}$ & $\begin{array}{l}3.81[2.35- \\
6.19]\end{array}$ & $<0.001^{\star}$ & $2.81[2.17-3.63]$ & $<0.001^{*}$ \\
\hline$\geq 65$ & $\begin{array}{l}3.91[3.03- \\
5.03]\end{array}$ & $<0.001^{\star}$ & $\begin{array}{l}4.43[2.62- \\
7.49]\end{array}$ & $<0.001^{\star}$ & $3.63[2.75-4.78]$ & $<0.001^{\star}$ \\
\hline Weight (Kg) & $\begin{array}{l}1.02[1.00- \\
1.04]\end{array}$ & $0.024^{\star}$ & $\begin{array}{l}1.02[0.99- \\
1.06]\end{array}$ & 0.187 & 1.03 [1.01-1.05] & $0.009 *$ \\
\hline \multicolumn{7}{|l|}{$\mathrm{BMI}\left(\mathrm{kg} / \mathrm{m}^{2}\right)$} \\
\hline$<25 \mathrm{~kg} / \mathrm{m}^{2}$ & Ref & & Ref & & Ref & \\
\hline $25 \leq B M 1<30 \mathrm{~kg} / \mathrm{m}^{2}$ & $\begin{array}{l}0.55[0.44- \\
0.71]\end{array}$ & $<0.001^{\star}$ & $\begin{array}{l}0.80[0.49- \\
1.30]\end{array}$ & 0.368 & $0.49[0.38-0.64]$ & $<0.001^{\star}$ \\
\hline$\geq 30 \mathrm{~kg} / \mathrm{m}^{2}$ & $\begin{array}{l}0.73[0.48- \\
1.10]\end{array}$ & 0.134 & $\begin{array}{l}0.93[0.42- \\
2.11]\end{array}$ & 0.875 & $0.63[0.40-1.00]$ & $<0.050 *$ \\
\hline Waist Circumference (Cm) & $\begin{array}{l}1.01[1.00- \\
1.02]\end{array}$ & $<0.001^{\star}$ & $\begin{array}{l}1.01[1.00- \\
1.02]\end{array}$ & $0.012^{\star}$ & $1.01[1.00-1.02]$ & $0.001 *$ \\
\hline \multicolumn{7}{|l|}{ Smoking history (\%) } \\
\hline Never smoked & Ref & & Ref & & Ref & \\
\hline Ex-smoker & $\begin{array}{l}1.04[0.83- \\
1.30]\end{array}$ & 0.753 & $\begin{array}{l}1.35[0.86- \\
2.14]\end{array}$ & 0.189 & $1.09[0.85-1.39]$ & 0.493 \\
\hline Current smoker & $\begin{array}{l}5.06[4.05- \\
6.31]\end{array}$ & $<0.001^{\star}$ & $\begin{array}{l}5.71[3.68- \\
8.86]\end{array}$ & $<0.001^{\star}$ & $5.7 \times[4.50-7.25]$ & $<0.001^{\star}$ \\
\hline \multicolumn{7}{|l|}{ Alcohol history (\%) } \\
\hline Never & Ref & & Ref & & Ref & \\
\hline $0-5$ Years & $\begin{array}{l}2.48[1.85- \\
3.32]\end{array}$ & $<0.001^{\star}$ & $\begin{array}{l}2.50[1.37- \\
4.56]\end{array}$ & $0.003^{*}$ & 2.48 [1.80-3.51] & $<0.001^{\star}$ \\
\hline 6-10 Years & $\begin{array}{l}2.76[1.85- \\
3.32]\end{array}$ & $<0.001^{\star}$ & $\begin{array}{l}3.38[1.72- \\
6.28]\end{array}$ & $<0.001^{\star}$ & 2.73 [1.90-3.94] & $<0.001^{\star}$ \\
\hline $11-15$ Years & $\begin{array}{l}2.79[1.92- \\
4.06]\end{array}$ & $<0.001^{*}$ & $\begin{array}{l}3.21[1.55- \\
6.61]\end{array}$ & $0.002^{\star}$ & 3.04 [2.03-4.54] & $<0.001^{*}$ \\
\hline$>15$ Years & $\begin{array}{l}1.97[1.57- \\
2.48]\end{array}$ & $<0.001^{\star}$ & $\begin{array}{l}1.52[0.93- \\
2.47]\end{array}$ & $0.092^{\star}$ & 2.11 [1.64-2.71] & $<0.001^{*}$ \\
\hline $\begin{array}{l}\text { Fasting Blood Glucose } \\
(\mathrm{mg} / \mathrm{dL})\end{array}$ & $\begin{array}{l}1.00[1.00- \\
1.01]\end{array}$ & $0.034^{\star}$ & $\begin{array}{l}1.01[1.00- \\
1.02]^{-}\end{array}$ & 0.007 & 1.00 [1.00-1.01] & 0.055 \\
\hline
\end{tabular}




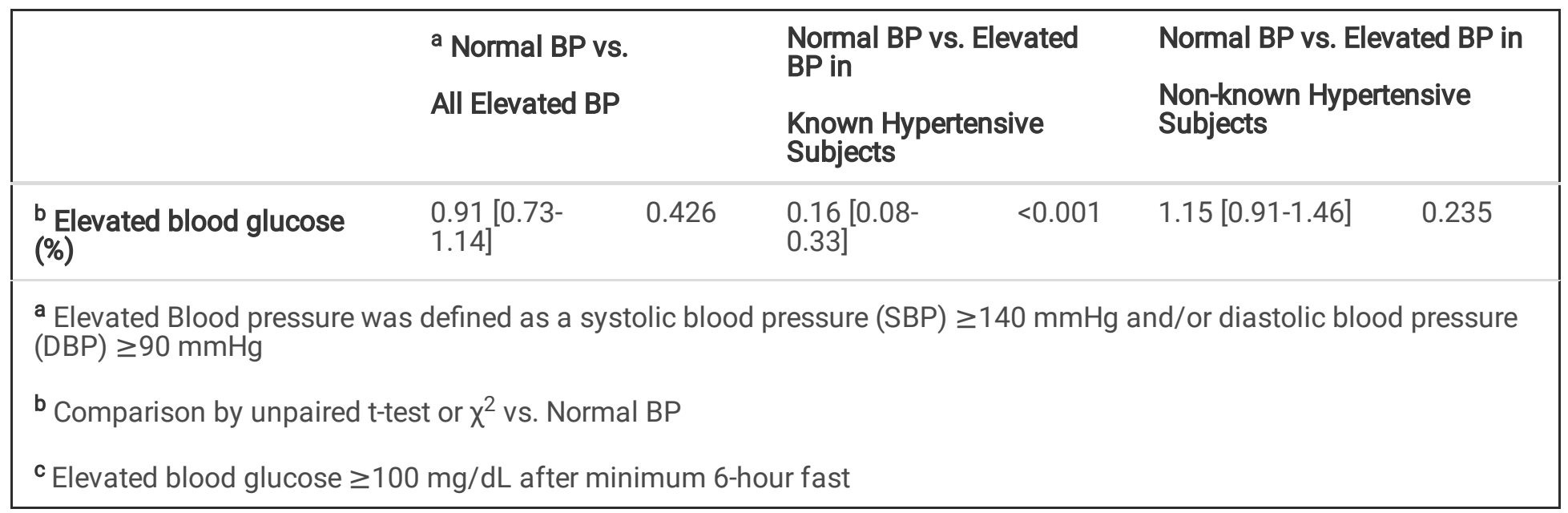

Table 2 caption: Table 2 shows results from the multivariate analysis assessing independent participants' characteristics associated to the elevated BP, comparison between each time the normal BP group vs elevated BP, vs poorly controlled BP and vs new discovered cases BP groups.

\section{Discussion}

This report revealed two main unexpected findings: A high rate of Elevated BP among individuals not known to have hypertension (18.7\%), a higher rate of elevated BP in individuals with a known diagnosis of hypertension (62.2\%), and high rates of elevated blood glucose (79.1\%). High rates of elevated BP and elevated BG identified through a health screening campaign in this Rwandan district were surprising given the rural characteristics of the district and relatively low population age (46.4 \pm 15.8 years).

Awareness and hypertension control in this study

This report identified a high prevalence of elevated BP in individuals not previously known to have hypertension. This finding confirms both a high prevalence and a poor awareness of HTN typical of ${ }^{17}$ especially in Sub-Sahara Africa ${ }^{6,22}$. However, it is lower compared to the pooled weighted awareness rate of $16.9 \%$ in 1990, 29.2\% in 2000 and $33.7 \%$ in 2010 reported by Adeloye $D$ et al ${ }^{23}$ from population-based studies on hypertension in Africa. The availability of data on awareness rates of hypertension in sub-Saharan Africa (SSA) in general, and from rural areas in particular, are scattered and generated by a wide range of studies differing in methodology thus limiting the opportunity for reliable comparisons ${ }^{7,24,25}$. However, the recent study by Chow CK et al ${ }^{26}$ reports that only one in three individual is aware of their hypertension status (i.e. higher than in our study), and about only $8 \%$ have their blood pressure controlled (i.e. lower than in our study). The poor treatment control in African settings has been largely reported by other authors, however the $37.8 \%$ reported rate by this study is higher than the reported average of $23.4 \% .{ }^{26}$ The high proportion of rural dwellers with uncontrolled hypertension in our study can be partially explained by geographically inaccessibility to health facilities for treatment monitoring.

High prevalence found in this study

This study identified an overall prevalence of Elevated BP of $21.2 \%$ (95\% Cl= 20.0-22.4\%). A prior population-based study in Rwanda estimated the prevalence of HTN in people between 15 and 64 years old at $15.3 \%$ (16.4\% for males and $14.4 \%$ for females) ${ }^{22}$, indicating that $\sim 1$ million people are living with HTN in Rwanda. The reported rate of elevated BP in this study was also lower than the $27.7 \%$ reported by a workplace-screening program conducted in an urban Ethiopian setting. ${ }^{27}$ Other studies from rural areas of Sub-Saharan Africa have reported variable rates of HTN prevalence that ranges from 5-52\% $8,28,29$. Adeloye $\mathrm{D}$ et al ${ }^{23}$ had estimated hypertension pooled prevalence pooled in Africa at $26.1 \%$ (95\% $\mathrm{Cl}$ : 23.6-33.6). In line with those other pooled data, the results presented in the current study confirm a serious concern of the rising prevalence of hypertension in rural Rwanda. This threat is further exacerbated by an under-resourced healthcare system; the 
nationwide network of healthcare clinics available to treat NCDs in Rwanda only serve approximately 80,000 patients, representing a coverage of $<10 \%{ }^{30}$. These data indicate that the majority of Rwandan adults with HTN are not only untreated, but undiagnosed.

\section{Participants' characteristics in this study}

The participant characteristics associated with elevated BP in this study are similar to the preliminary data reported by Muggli F. et $\mathrm{al}^{28}$ from another screening event held in the rural area of the District of Nyaruguru (Southern Rwanda) which found a much low prevalence of hypertension at $8.8 \%$. However, that screening event reported a median age of 32 years, much younger than $46 \pm 16$ years reported in this study. This lower age likely contributes to the low prevalence of hypertension found in their report. As reported in other studies, 7,10,17,29 gender was not significantly associated to elevated BP in our study. However, consistent with other studies, ${ }^{25,31,32}$ advancing age was a significant predictor of elevated BP in this study.

The association between overweight and elevated blood pressure has been long-established, including in African populations. ${ }^{15,33-35}$ This study revealed a high prevalence of overweight and obesity as noted in other prior studies conducted in rural Rwandan areas ${ }^{22}$. The relationship between BP and anthropometric indices such as BMI, WC, waist to hip ratio (WHpR), and waist to height ratio (WHtR) have been described in others studies. ${ }^{33}$ Our study was not powered to assess this comparison between overweight indices, and some indices were not available for analysis. Therefore we added all raw data on weight, height, $\mathrm{BMI}$ and WC into analysis both univariate and multivariate after assess collinearity with correlation matrix between variables. The association between the BMI categories and the elevated BP was not conclusive in our study probably due to small sample size in cells in contrast with WC. Nevertheless, this finding is unexpected and further work is needed to validate the association identified in this study since these are in contrast with other reports from rural India ${ }^{34}$ and Nigerian ${ }^{35}$ which identify a higher BMI as a major risk factor for hypertension ${ }^{18,36,37}$.

Other risk factors identified in multivariable analysis as independently associated to elevated BP are in line with previous Rwanda WHO STEPs study by Nahimana MR et al ${ }^{22}$. In their nationwide study, a logistic regression model revealed that age, alcohol consumption, blood glucose levels, and raised BMI were significantly associated with hypertension, a finding confirmed in this study.

Implication for strategy for the prevention, diagnosis and treatment of hypertension in Rwanda

This study brings additional evidence to support tailored measures for the prevention, diagnosis and treatment of hypertension in rural populations in Rwanda. Recent reviews analysing root causes for poor blood pressure control in Rwanda ${ }^{38}$ and in Eastern Sub-Saharan Africa ${ }^{39}$ highlight this unmet healthcare need. On a global scale, the World Health Organization (WHO) has created a target to reduce heart attacks and stroke by $25 \%$ by $2025^{17}$, and the World Heart Federation (WHF) launched a roadmap focusing on raised BP awareness, treatment, and control during the 2015 World Health Assembly in Geneva. ${ }^{40}$ Monitoring through systematically organized periodic screening campaigns for HTN, diabetes, and other NCD risk factors in rural population remains a key strategy for optimizing treatment and control ${ }^{24}$. Early detection with opportunistic screening campaigns can also mitigate multiple barriers like poor health education literacy ${ }^{38}$ and low socio-economic status. ${ }^{39}$ However, given the need to balance competing healthcare priorities including infectious diseases, nutritional deficiencies, and maternal and perinatal morbidity and mortality, a reallocation of healthcare resources towards continuous monitoring of NCDs in LMICs is necessary. ${ }^{6}$

Study limitations

This study fills in a scientific data gap and its large sample size is adequate for subgroup comparisons. This is also one of the first studies to characterize the blood pressure and blood glucose profiles in a remote rural area in Rwanda through a 
community screening. However it has also some limitations. First, given the current study is not a systematic populationbased screening, bias from participant self-selection likely influenced the results of this study. Second, given the crosssectional design of this screening study, we are unable to determine temporality and causality in the study; therefore, causation can only be inferred. Third, the study reports only elevated BP and not prevalence of hypertension because the three blood pressure measurements were performed only on one occasion. Fourth, we were unable to explore the contribution of other risk factors such as unhealthy diet, salt intake, and psychosocial stress on the prevalence of hypertension because the related information were not available during casual data collection. Additionally, the quantification of alcohol intake and smoking where rather empirical in the region where traditional alcoholic drinks ${ }^{41}$ and traditional pipe smoking were hard to define according to international standards ${ }^{42}$. There might be also social desirability biases to underestimating some of the lifestyle and behavioural questions, such as smoking and alcohol consumptions. Despite these limitations, the study makes significant contribution and fills a substantial gap in the current Rwanda and regional context. The use of standardized and robust methodologies, tools and high response rate observed in the study increased its representativeness and strengthens its value in informing the CVDs prevention by enabling tailored preventive measures and optimize the treatment control.

\section{Conclusion}

This opportunistic screening findings confirm a high rate of newly discovered elevated BP and poor control among rural population in Rwanda. This study identified age, current smoking, and alcohol history and waist circumference to be the risks associated with elevated BP. Having such high rate of newly discovered abnormal BP from that rural population would imply an epidemiological risk profile transition for hypertension, that needs further studies. Nevertheless, these data support the need to strengthen also in rural areas of Rwanda an adequate strategy for the prevention, early diagnosis and treatment of hypertension. Future longitudinal studies to analyse in more details the specific CVDs risk in that population are needed.

\section{Abbreviations}

BP: Blood pressure, BG: Blood glucose, BMI : Body Mass Index, CVDs: Cardiovascular diseases, DBP: Diastolic blood pressure HC: Health center, HBC: Health Belief Models, HTN: Hypertension, LMICs: Low middle income countries, NCDs: Non- communicable diseases Center, NISR: National Institute of Statistics of Rwanda, RBC: Rwanda Biomedical center, SBP: Systolic Blood pressure, WC: Waist Circumference, WHpR: Waist to hip ratio, WHtR: Waist to height ratio, WHO: World health organization, WHF: World heart federation.

\section{Declarations}

\section{Ethics approval and consent to participate}

Routinely collected program data analyzed for this study are maintained by the Rwanda Biomedical Centre (RBC), Division of Non-communicable Diseases. The ethical procedures for the collection of these data were governed by the Medical Research Council of Rwanda, and site authorizations were obtained from the Ministry of Health for hosting sites. Secondary analyses of routinely collected and de-identified data are exempted for additional ethical clearance by RBC. Approval (No. $3653 / R B C / 2021)$ for utilization of the data was obtained by RBC. Verbal consent was obtained from all eligible participants to the screening before blood sample and interview based data collection. The study was conducted in accordance with the principles of the Declaration of Helsinki and local Rwandan regulations.

\section{Author Contributions}

Conceptualization, methodology, data collection: EN, EH, GN, SD, and FU; Data curation and data analysis: RM, MT and JNU; Original draft preparation: RM, MT, EM, JNU, LT, AB, TC, MB, DR, LDF and MT; Review and Editing: EN, EM, RM, AN, VDR, KS, $L T, A B, T W C, M B, D R, L D F$ and MT. All authors have read and agreed to the published version of the manuscript. 


\section{Consent for publication}

Study participants consent for publication was included in their verbal consent to participate in the study and approved by the Rwanda Biomedical Center (No. 3653/RBC/2021) according the Medical Research Council of Rwanda guidelines.

\section{Funding}

This research was funded by Partners in Health/Inshuti Mu Buzima (PHI/IMB) and Government of Rwanda through Rwanda Biomedical Center (Ministry of Health). PHI/IMB is an international non-profit organization that supports the Ministry of health in implementation of health services in three districts namely Burera, Kirehe and Kayonza. The funding parties have no involvement in the design of the study, analysis, interpretation of data or writing this publication.

\section{Acknowledgments}

We would like to thank the staff of Partners on Health/Inshuti mu Buzima for their support and contributions towards the successful completion of the study.

\section{Competing Interest}

The authors declare no conflict of interest

\section{Availability and data materials}

The dataset used and/or analyzed during this study is available from the corresponding author on reasonable request

\section{References}

1. A. A. Baumann, V. Mutabazi, A. L. Brown, C. Hooley, D. Reeds, C. Ingabire, V. Ndahindwa, A. Nishimwe, W. T. Cade, L. de Las Fuentes, E. K. Proctor, S. Karengera, K. B. Schecthman, C. W. Goss, K. Yarasheski, B. Newsome, E. Mutimura, V. G. Davila-Roman. Dissemination and Implementation Program in Hypertension in Rwanda: Report on Initial Training and Evaluation. Glob Heart 2019;14:135-41.

2. C. M. Lawes, S. Vander Hoorn, A. Rodgers, Hypertension International Society of. Global burden of blood-pressurerelated disease, 2001. Lancet 2008;371:1513-8.

3. P. Kotwani, D. Kwarisiima, T. D. Clark, J. Kabami, E. H. Geng, V. Jain, G. Chamie, M. L. Petersen, H. Thirumurthy, M. R. Kamya, E. D. Charlebois, D. V. Havlir, Search Collaboration. Epidemiology and awareness of hypertension in a rural Ugandan community: a cross-sectional study. BMC Public Health 2013;13:1151.

4. D. C. D. Mathers Loncar. Updated projections of global mortality and burden of disease, 2002-2030: data sources, methods and results. World Health Organization 2005:1-130.

5. A. K. Amegah. Tackling the Growing Burden of Cardiovascular Diseases in Sub-Saharan Africa. Circulation 2018;138:2449-51.

6. M. Twagirumukiza, D. De Bacquer, J. G. Kips, G. de Backer, R. V. Stichele, L. M. Van Bortel. Current and projected prevalence of arterial hypertension in sub-Saharan Africa by sex, age and habitat: an estimate from population studies. J Hypertens 2011;29:1243-52.

7. A. E. Schutte, N. Srinivasapura Venkateshmurthy, S. Mohan, D. Prabhakaran. Hypertension in Low- and Middle-Income Countries. Circ Res 2021;128:808-26.

8. C. Agyemang. Rural and urban differences in blood pressure and hypertension in Ghana, West Africa. Public Health 2006;120:525-33.

9. O. John, N. R. C. Campbell, T. M. Brady, M. Farrell, C. Varghese, A. Velazquez Berumen, L. A. Velez Ruiz Gaitan, N. Toffelmire, M. Ameel, M. Mideksa, M. G. Jaffe, A. E. Schutte, T. Khan, L. P. Lopez Meneses. The 2020 "WHO Technical 
Specifications for Automated Non-Invasive Blood Pressure Measuring Devices With Cuff". Hypertension 2021;77:80612.

10. J. Banyangiriki, J. Phillips. Prevalence of Hypertension among Working Adults in Rwanda. Iran J Public Health 2013;42:925-6.

11. B. Kavishe, S. Biraro, K. Baisley, F. Vanobberghen, S. Kapiga, P. Munderi, L. Smeeth, R. Peck, J. Mghamba, G. Mutungi, E. Ikoona, J. Levin, M. A. Bou Monclus, D. Katende, E. Kisanga, R. Hayes, H. Grosskurth. High prevalence of hypertension and of risk factors for non-communicable diseases (NCDs): a population based cross-sectional survey of NCDS and HIV infection in Northwestern Tanzania and Southern Uganda. BMC Med 2015;13:126.

12. C. L. Jones, J. D. Jensen, C. L. Scherr, N. R. Brown, K. Christy, J. Weaver. The Health Belief Model as an explanatory framework in communication research: exploring parallel, serial, and moderated mediation. Health Commun 2015;30:566-76.

13. National Institute of Statistics Rwanda. EICV 3 Thematic Report -Rwanda. 2012.

14. World Health Organization. WHO STEPS Surveillance Manual: The WHO STEPwise approach to chronic disease risk factor surveillance. 2005.

15. W.H.O Expert Consultation. Waist Circumference and Waist-Hip Ratio Report of a WHO Expert Consultation, Geneva, 811 December 20082011.

16. Y. Xie, M. Ma, Z. Li, X. Guo, G. Sun, Z. Sun, J. Zheng, Y. Sun, L. Zheng. Elevated blood pressure level based on 2017 ACC/AHA guideline in relation to stroke risk in rural areas of Liaoning province. BMC Cardiovasc Disord 2019;19:258.

17. A. Dzudie, D. Ojji, B. C. Anisiuba, B. A. Abdou, R. Cornick, A. Damasceno, A. L. Kane, A. O. Mocumbi, A. Mohamed, G. Nel, E. Ogola, B. Onwubere, H. Otieno, B. Rainer, A. Schutte, I. T. Ali, M. Twagirumukiza, N. Poulter, B. Mayosi, Pascar Hypertension Task Force members. Development of the roadmap and guidelines for the prevention and management of high blood pressure in Africa: Proceedings of the PASCAR Hypertension Task Force meeting: Nairobi, Kenya, 27 October 2014. Cardiovasc J Afr 2015;26:82-5.

18. P. K. Whelton, R. M. Carey, W. S. Aronow, D. E. Casey, Jr., K. J. Collins, C. Dennison Himmelfarb, S. M. DePalma, S. Gidding, K. A. Jamerson, D. W. Jones, E. J. MacLaughlin, P. Muntner, B. Ovbiagele, S. C. Smith, Jr., C. C. Spencer, R. S. Stafford, S. J. Taler, R. J. Thomas, K. A. Williams, Sr., J. D. Williamson, J. T. Wright, Jr. 2017 ACC/AHA/AAPA/ABC/ACPM/AGS/APhA/ASH/ASPC/NMA/PCNA Guideline for the Prevention, Detection, Evaluation, and Management of High Blood Pressure in Adults: A Report of the American College of Cardiology/American Heart Association Task Force on Clinical Practice Guidelines. Circulation 2018;138:e484-e594.

19. S. Solomon, W. Mulugeta. Disease burden and associated risk factors for metabolic syndrome among adults in Ethiopia. BMC Cardiovasc Disord 2019;19:236.

20. American Diabetes Association. Diagnosis and classification of diabetes mellitus. Diabetes Care 2009;32 Suppl 1:S627.

21. Y. Heianza, Y. Arase, K. Fujihara, H. Tsuji, K. Saito, S. D. Hsieh, S. Kodama, H. Shimano, N. Yamada, S. Hara, H. Sone. Screening for pre-diabetes to predict future diabetes using various cut-off points for $\mathrm{HbA}(1 \mathrm{c})$ and impaired fasting glucose: the Toranomon Hospital Health Management Center Study 4 (TOPICS 4). Diabet Med 2012;29:e279-85.

22. M. R. Nahimana, A. Nyandwi, M. A. Muhimpundu, O. Olu, J. U. Condo, A. Rusanganwa, J. B. Koama, C. T. Ngoc, J. B. Gasherebuka, M. O. Ota, J. C. Okeibunor. A population-based national estimate of the prevalence and risk factors associated with hypertension in Rwanda: implications for prevention and control. BMC Public Health 2017;18:2.

23. D. Adeloye, C. Basquill. Estimating the prevalence and awareness rates of hypertension in Africa: a systematic analysis. PLoS One 2014;9:e104300.

24. J. Jin. Screening for Hypertension in Adults. JAMA 2021;325:1688.

25. G. Yonga, F. O. Okello, J. L. Herr, A. Mulvaney, E. N. Ogola. Healthy Heart Africa: a prospective evaluation of programme outcomes on individuals' hypertension awareness, screening, diagnosis and treatment in rural Kenya at 12 months. 
Cardiovasc J Afr 2020;31:9-15.

26. C. K. Chow, K. K. Teo, S. Rangarajan, S. Islam, R. Gupta, A. Avezum, A. Bahonar, J. Chifamba, G. Dagenais, R. Diaz, K. Kazmi, F. Lanas, L. Wei, P. Lopez-Jaramillo, L. Fanghong, N. H. Ismail, T. Puoane, A. Rosengren, A. Szuba, A. Temizhan, A. Wielgosz, R. Yusuf, A. Yusufali, M. McKee, L. Liu, P. Mony, S. Yusuf, Pure Study investigators. Prevalence, awareness, treatment, and control of hypertension in rural and urban communities in high-, middle-, and low-income countries. JAMA 2013;310:959-68.

27. K. Angaw, A. F. Dadi, K. A. Alene. Prevalence of hypertension among federal ministry civil servants in Addis Ababa, Ethiopia: a call for a workplace-screening program. BMC Cardiovasc Disord 2015;15:76.

28. Franco Muggli, Gianfranco Parati, Paolo Suter, Mario Bianchetti, Dragana Radovanovic, Alice Umulise, Bienvenu Muvunyi, Evariste Ntaganda. Blood Pressure in a Population of a Rural Area of Rwanda: Preliminary Data. Journal of Hypertension 2021;39:e400.

29. P. B. Katchunga, M. Twagirumukiza, Y. Kluyskens, D. Kaishusha, M. Baguma, A. Bapolisi, J. Cikomola, T. Ntabure, S. Callens, J. R. M'Buyamba-Kabangu, L. Van Bortel. Blood pressure in the Congolese adult population of South Kivu, Democratic Republic of Congo: Preliminary results from the Bukavu Observ Cohort Study. Rev Epidemiol Sante Publique 2015;63:339-45.

30. Rwanda Biomedical Center. Rwandans encouraged to go for early screening to prevent NCDs. 2021;2021.

31. B. Everett, A. Zajacova. Gender differences in hypertension and hypertension awareness among young adults. Biodemography Soc Biol 2015;61:1-17.

32. P. K. Drain, T. Hong, A. Hajat, M. Krows, S. Govere, H. Thulare, M. Y. S. Moosa, I. Bassett, C. Celum. Integrating hypertension screening at the time of voluntary HIV testing among adults in South Africa. PLoS One 2019;14:e0210161.

33. B. T. Gutema, A. Chuka, G. Ayele, N. D. Megersa, M. Bekele, A. Baharu, M. K. Gurara. Predictive capacity of obesity indices for high blood pressure among southern Ethiopian adult population: a WHO STEPS survey. BMC CardiovasC Disord 2020;20:421.

34. P. R. Deshmukh, S. S. Gupta, A. R. Dongre, M. S. Bharambe, C. Maliye, S. Kaur, B. S. Garg. Relationship of anthropometric indicators with blood pressure levels in rural Wardha. Indian J Med Res 2006;123:657-64.

35. R. A. Adedoyin, C. E. Mbada, L. A. Bisiriyu, R. A. Adebayo, M. O. Balogun, A. O. Akintomide. Relationship of anthropometric indicators with blood pressure levels and the risk of hypertension in Nigerian adults. Int J Gen Med 2008;1:33-40.

36. J. R. Sharma, S. E. Mabhida, B. Myers, T. Apalata, E. Nicol, M. Benjeddou, C. Muller, R. Johnson. Prevalence of Hypertension and Its Associated Risk Factors in a Rural Black Population of Mthatha Town, South Africa. Int J Environ Res Public Health 2021;18.

37. R. O. Shittu, L. O. Odeigah, K. O. Fakorede, B. A. Sikiru, A. G. Sule, Y. Musah, F. M. Adeyemi. Prevalence and correlates of hypertension-outcome of a free medical screening in Oke-Ogun area of Oyo state, Nigeria, West Africa. J Am Soc Hypertens 2018;12:268-74.

38. J. P. Sibomana, R. L. McNamara, T. D. Walker. Patient, clinician and logistic barriers to blood pressure control among adult hypertensives in rural district hospitals in Rwanda: a cross-sectional study. BMC Cardiovasc Disord 2019;19:231.

39. M. M. Sorato, M. Davari, A. Kebriaeezadeh, N. Sarrafzadegan, T. Shibru, B. Fatemi. Reasons for poor blood pressure control in Eastern Sub-Saharan Africa: looking into 4P's (primary care, professional, patient, and public health policy) for improving blood pressure control: a scoping review. BMC Cardiovasc Disord 2021;21:123.

40. A. J. Adler, D. Prabhakaran, P. Bovet, D. S. Kazi, G. Mancia, V. Mungal-Singh, N. Poulter. Reducing Cardiovascular Mortality Through Prevention and Management of Raised Blood Pressure: A World Heart Federation Roadmap. Glob Heart 2015;10:111-22. 
41. N. K. Morojele, E. W. Dumbili, I. S. Obot, C. D. H. Parry. Alcohol consumption, harms and policy developments in subSaharan Africa: The case for stronger national and regional responses. Drug Alcohol Rev 2021;40:402-19.

42. J. J. Noubiap, J. R. Nansseu, F. T. Endomba, A. Ngouo, J. R. Nkeck, U. F. Nyaga, A. D. Kaze, J. J. Bigna. Active smoking among people with diabetes mellitus or hypertension in Africa: a systematic review and meta-analysis. Scientific reports 2019;9:588.

\section{Figures}

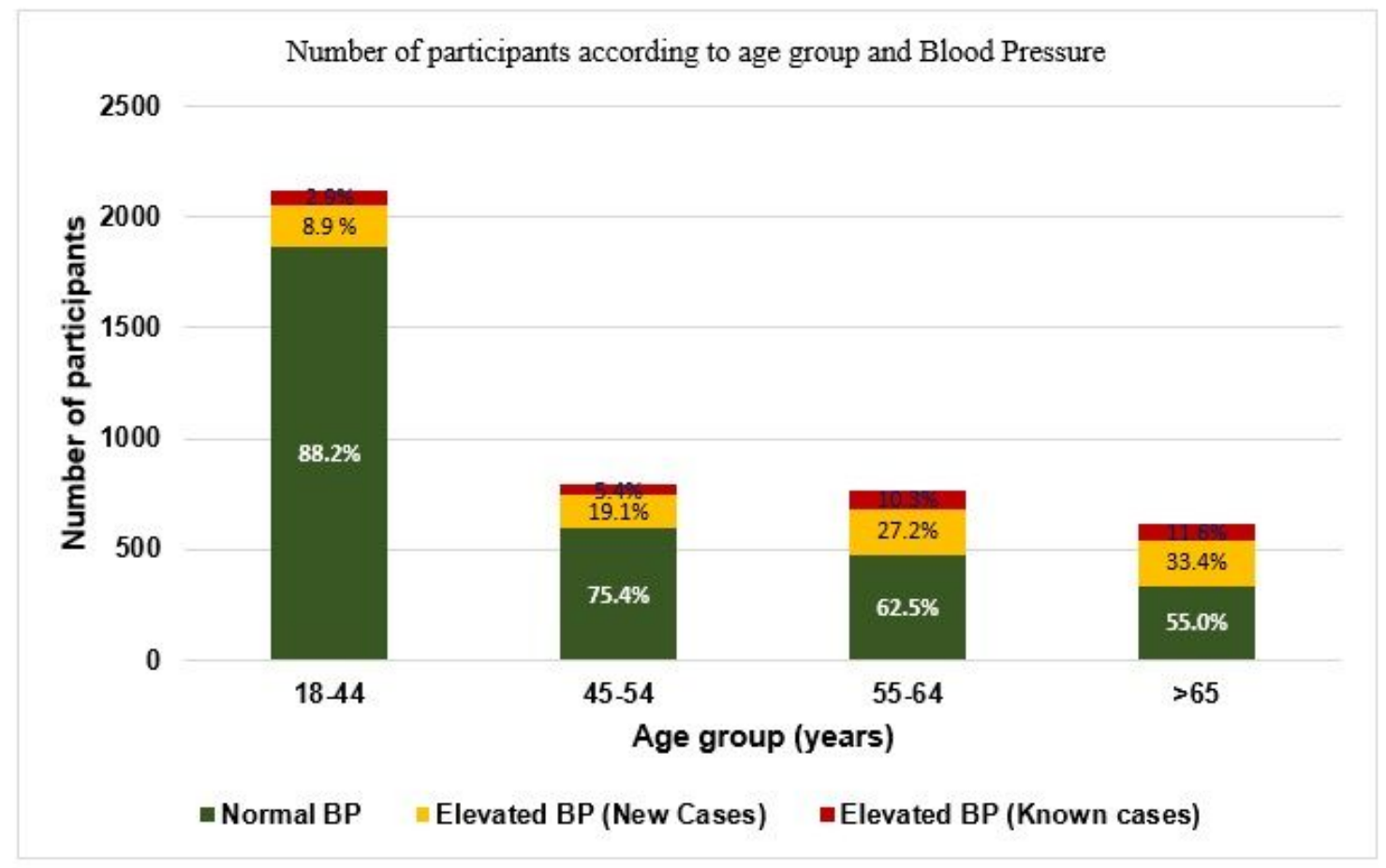

\section{Figure 1}

Number of participants according to age group and Blood Pressure 


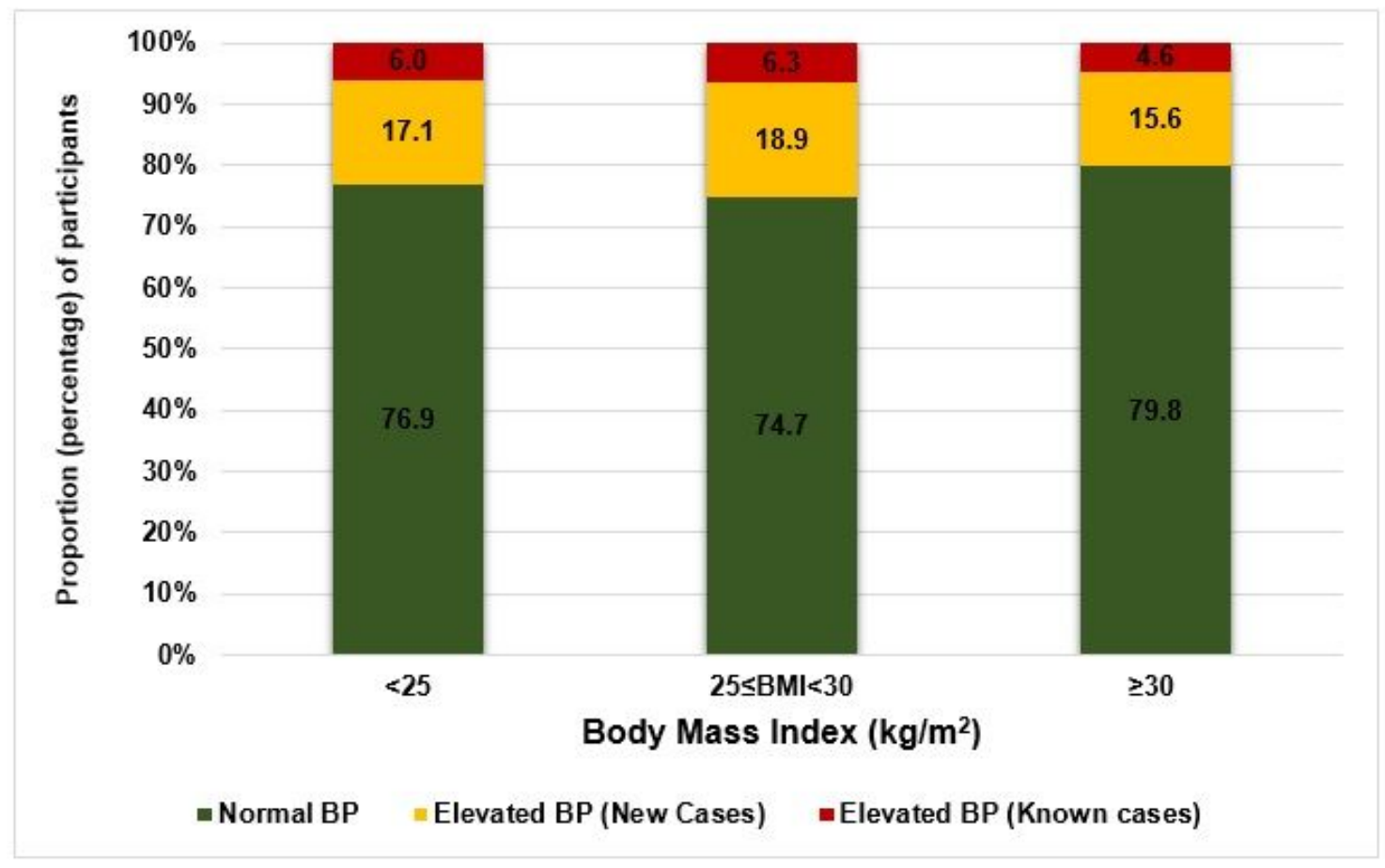

Figure 2

Number of participants by BMI and BP class

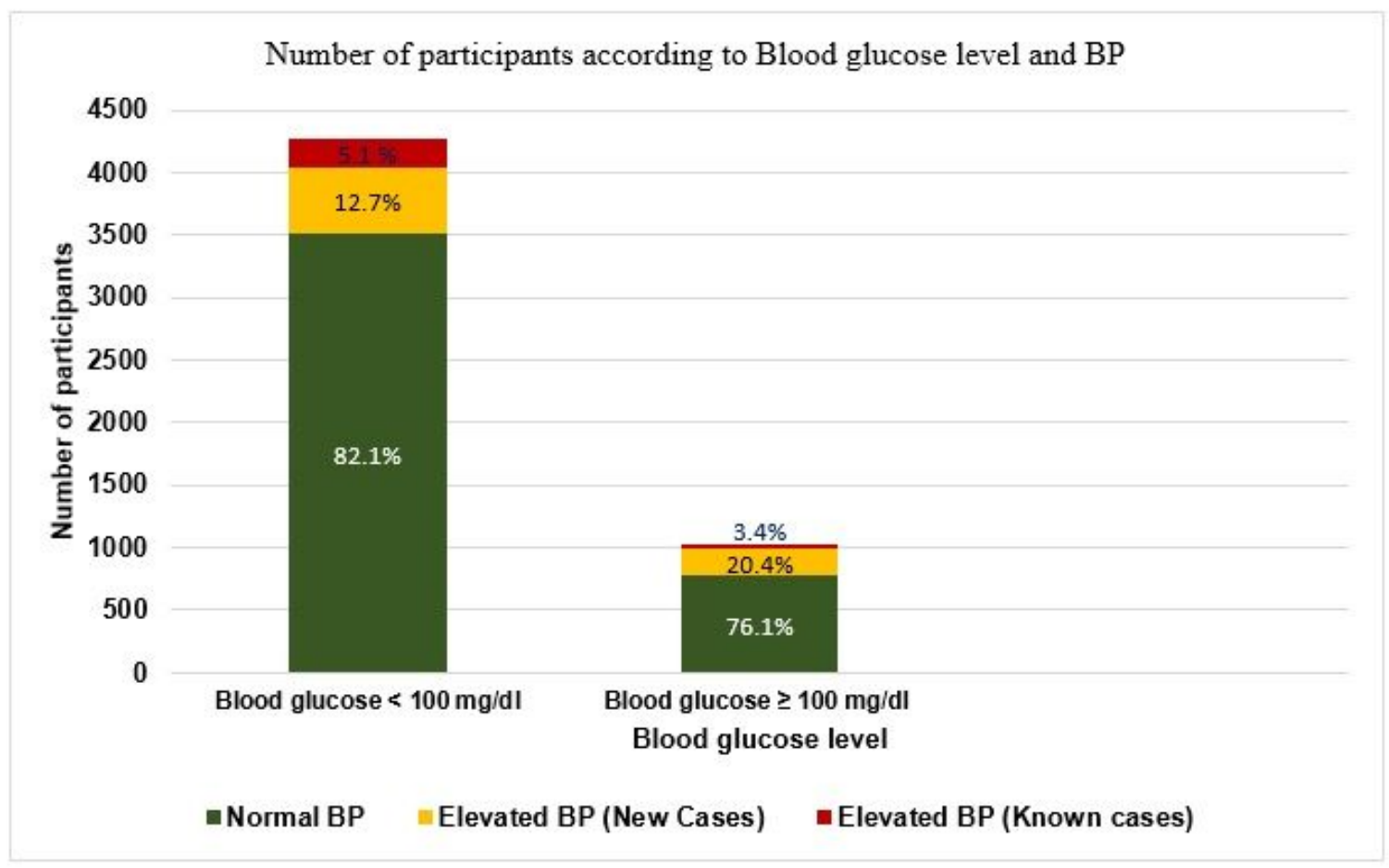

Figure 3

Number of participants according to Blood glucose level and BP

\section{Supplementary Files}


This is a list of supplementary files associated with this preprint. Click to download.

- HighratesElevatedBPRuralAreaRwandaSupplementaryFile.docx 